\title{
Evaluation of mechanical and thermal properties of microwave irradiated poly (styrene-co-methyl methacrylate)/graphene nanocomposites
}

\author{
Mukarram Zubair, Jobin Jose \& Mamdouh A. Al-Harthi
}

To cite this article: Mukarram Zubair, Jobin Jose \& Mamdouh A. Al-Harthi (2015) Evaluation of mechanical and thermal properties of microwave irradiated poly (styrene-co-methyl methacrylate)/graphene nanocomposites, Composite Interfaces, 22:7, 595-610, DOI: $10.1080 / 09276440.2015 .1055960$

To link to this article: http://dx.doi.org/10.1080/09276440.2015.1055960

Published online: 19 Jun 2015.

Submit your article to this journal $\llbracket$

Џ Article views: 59

View related articles $₫$

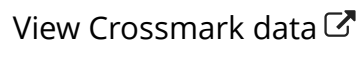




\title{
Evaluation of mechanical and thermal properties of microwave irradiated poly (styrene-co-methyl methacrylate)/graphene nanocomposites
}

\author{
Mukarram Zubair ${ }^{\mathrm{a}}$, Jobin Jose ${ }^{\mathrm{b}}$ and Mamdouh A. Al-Harthi ${ }^{\mathrm{c}, \mathrm{d} *}$ \\ ${ }^{a}$ Department of Environmental Engineering, University of Dammam, Dammam 31982, \\ Saudi Arabia; ${ }^{b}$ Center for Engineering Research, King Fahd University of Petroleum \& Minerals, \\ Dhahran 31261, Saudi Arabia; ${ }^{c}$ Department of Chemical Engineering, King Fahd University of \\ Petroleum \& Minerals, Dhahran 31261, Saudi Arabia; ${ }^{d}$ Center of Research Excellence in \\ Nanotechnology, King Fahd University of Petroleum \& Minerals, Dhahran 31261, Saudi Arabia
}

(Received 4 February 2015; accepted 26 May 2015)

\begin{abstract}
Poly (styrene-co-methyl methacrylate) (P(S-co-MMA)) was blended with pristine graphene $(\mathrm{G})$ by melt mixing technique and treated under microwave irradiation. The nanocomposites were irradiated for 5 and $10 \mathrm{~min}$ at frequency $1245 \mathrm{MHz}$. Structure changes in the irradiated nanocomposites were observed by Fourier transform infrared spectroscopy and Raman spectroscopy. The irradiated composites showed a significant increase in the storage modulus i.e. $21 \%$ for $0.1 \%$ and $31 \%$ for $1 \%$ graphene polymer composites after 5 min irradiation. However at higher irradiation (10 min), degradation of nanocomposites was observed. The concept of improvement of interfacial interaction between graphene and P(S-co-MMA) chains at 5-min microwave exposure and degradation of nanocomposites at higher irradiation duration was assessed and supported by X-ray diffraction and scanning electron microscopy.
\end{abstract}

Keywords: styrene; methyl methacrylate; copolymer; graphene; microwave radiation

\section{Introduction}

During the past two decades, nanocomposites, especially carbon-based nanomaterials, have become a novel class of material. When incorporated into a polymer matrix, they have revealed remarkably improved properties, at very low loading contents. In particular, graphene and its polymer composites have attracted tremendous applications in modern science and technology.[1,3] Being the 'thinnest material' in the universe, its unique properties make graphene more demanding in different technological fields such as conducting films,[4] sensors,[5] super capacitors,[6] nanoelectronics,[7] batteries,[8] and bio-medical applications.[9]

Polystyrene and poly (methyl methacrylate) are widely used commodity plastics after polyolefin. They are productively applied in different fields such as bio materials, protective coatings, microelectronics, tissue engineering, and solar technology.[10-13] Incorporation of nanofillers such as carbon nanotubes and graphene into the polymer matrix can considerably enhance mechanical and thermal properties, [2,14,15] which is desirable for different kinds of applications.

\footnotetext{
*Corresponding author. Email: mamdouh@kfupm.edu.sa
} 
Melt mixing is a widely used technique to prepare polymer nanocomposites. It is an easy, economical, and efficient technique in which high temperature and strong shear forces are employed to obtain efficient mixing between polymer matrix and nanofiller. During melt mixing, the polymer chains may degrade.[16] This can lead to better dispersion and covalent bond formation of nanofillers with the polymer chains.[17] To achieve full improvement in the properties of polymer/nanofiller composites, the most challenging step is to achieve a high level of homogenous dispersion and interaction between the nanofiller and the polymer matrix. Different approaches such as the use of peroxide during melt mixing,[18] functionalization of nanoparticles [19-21] and implication of low molecular weight polymer chains [22] have been investigated, but scientists are still looking for a more appropriate method to attain better interaction between the graphene and the polymer matrix.

Irradiation is a widely accepted and useful technique to modify the properties of polymer nanocomposites.[23] The irradiation process causes major reactions such as cross-linking, chain scission (degradation), formation of oxygen-based functionalities (oxidation), and grafting (in the presence of monomers).[24] Similarly, when radiation is absorbed on the surface of graphene, defects form on graphene [25] which results in a change of the structure of graphene. This free radical formation in polymer chains and disorder in graphene structure after irradiation may provide improved dispersion and hence a strong interfacial interaction between the graphene and the polymer matrix. Compared to other radiation techniques, microwave radiation is an fast, cheap, and green technique.[26] It was extensively used for synthesis of polymer composites [27], but so far very few studies has been performed [28,29] to investigate the improvement of interaction between graphene and copolymer composites using microwave radiation.

In this article, the poly (styrene-co-methyl methacrylate) (P(S-co-MMA))/graphene composites were prepared via melt blending and exposed to microwave radiation. The resultant samples were characterized by various techniques to study the influence of melt blending, filler content, and particularly microwave radiation on the interaction between $\mathrm{P}(\mathrm{S}-\mathrm{co}-\mathrm{MMA})$ and graphene.

\section{Experimental}

\subsection{Materials}

Styrene (99\%), methyl methacrylate (MMA, 99\%), and benzoyl peroxide were purchased from Sigma-Aldrich and used as received. Tetrahydrofuran (THF) and methanol were obtained from Pure Chemika. Graphene (96-99\%, 50-100 nm) was purchased from Grafen Chemical Industries Co. (Turkey).

\subsection{Synthesis of poly (styrene methyl methacrylate) copolymer}

$\mathrm{P}(\mathrm{S}-\mathrm{co}-\mathrm{MMA})$ copolymer is produced by free radical polymerization. Benzoyl peroxide of $0.1 \mathrm{wt} \%$ of the total volume of monomers was used as an initiator. Reaction was carried out in a round bottom flask equipped with a magnetic stirrer at $110{ }^{\circ} \mathrm{C}$ for $5 \mathrm{~h}$ under a nitrogen environment. After the reaction, THF $(60 \mathrm{ml}$ per $10 \mathrm{ml}$ of monomer) was added to the round bottom flask and stirred for 2-4 days to dissolve the product. The dissolved polymer solution was precipitated with an excess amount of methanol and then dried in an oven at $40{ }^{\circ} \mathrm{C}$ for $24 \mathrm{~h}$. 


\subsection{Preparation of poly (styrene methyl methacrylate)/graphene (PG) composite}

$\mathrm{P}(\mathrm{S}-\mathrm{co}-\mathrm{MMA}) /$ graphene nanocomposites were prepared using a Brabender torque rheometer. Different percentages of graphene $(0.1,0.3$, and $1 \mathrm{wt} \%)$ were added to $\mathrm{P}$ (S-co-MMA) copolymer and mixed for $10 \mathrm{~min}$ at a temperature of $180{ }^{\circ} \mathrm{C}$ at a speed of $60 \mathrm{rpm}$. Thin sheets of the composites with an approximate thickness of $1 \mathrm{~mm}$ were prepared by compression molding for $8 \mathrm{~min}$ at a temperature of $140{ }^{\circ} \mathrm{C}$ under a pressure of $97 \mathrm{MPa}$ and cooled to room temperature. Table 1 illustrates the composition of different samples produced in this study.

\subsection{Microwave irradiation method}

The microwave irradiation of the $\mathrm{P}(\mathrm{S}-\mathrm{co}-\mathrm{MMA})$ /graphene composite was carried out at frequency of $2450 \mathrm{MHz}$ at fixed power of $1000 \mathrm{~W}$ with different treatment times. The irradiation was carried out using a domestic microwave oven with an internal turn table.

The details of the procedure for irradiation of the samples are given below.

- Samples of dimension $(4 \times 10 \times 1 \mathrm{~mm})$ were treated at different treatment times at a constant power of $1000 \mathrm{~W}$ in the presence of air.

- The samples were irradiated at two different durations (5 and $10 \mathrm{~min}$ ) with $60 \mathrm{~s}$ for each cycle in the presence of air. After each cycle of irradiation, the sample was cooled to room temperature (taking about $120 \mathrm{~s}$ ) to avoid the effect of heat on the polymer graphene composite sample.

\subsection{Characterization}

\subsubsection{Spectroscopic analysis}

The FTIR spectra were recorded using a Nicolet 6700 spectrometer with resolution of $4 \mathrm{~cm}^{-1}$. The functional groups such as carbonyl and hydroxyl groups were compared before and after irradiation in a band range of $1700-1725$ and $3000-3450 \mathrm{~cm}^{-1}$, respectively. For Raman spectroscopy, a Raman Aramis (Horiba JobinYvon) instrument with laser power of $0.7 \mathrm{~mW}$ and wavelength of $473 \mathrm{~nm}$ was used. The composition of styrene and methyl methacrylate in the co-polymer was calculated using NMR spectra estimated at room temperature using a Bruker $500 \mathrm{MHz}$ spectrometer at resonance frequency of $500 \mathrm{MHz}$.

\subsubsection{Dynamic mechanical analysis}

The dynamic mechanical properties of the samples before and after irradiation were investigated in a temperature range from 40 to $160{ }^{\circ} \mathrm{C}$ in the tension mode at a heating

Table 1. Composition of $\mathrm{P}(\mathrm{S}-\mathrm{co}-\mathrm{MMA})$ and its composites.

\begin{tabular}{lccc}
\hline Sample name & $\begin{array}{c}\text { Copolymer composition } \\
\text { P(S-co-MMA) }\end{array}$ & $\begin{array}{c}\text { P(S-co-MMA) } \\
\text { content }(\mathrm{g})\end{array}$ & $\begin{array}{c}\text { Graphene } \\
\text { content }(\mathrm{mg})\end{array}$ \\
\hline P(S-co-MMA) & $70.6 / 29.4$ & 40 & 0 \\
PG(0.1) & $70.6 / 29.4$ & 40 & 40 \\
PG(0.3) & $70.6 / 29.4$ & 40 & 120 \\
PG(1.0) & $70.6 / 29.4$ & 40 & 400 \\
\hline
\end{tabular}


rate of $5{ }^{\circ} \mathrm{C} / \mathrm{min}$ and a frequency of $1 \mathrm{~Hz}$ using a Perkin Elmer DMA Q-800. The dynamic mechanical properties were tested under nitrogen environment at a load of $5 \mathrm{~N}$ with the average sample size $4 \times 10 \times 1 \mathrm{~mm}$.

\subsubsection{Differential scanning calorimetry}

The glass transition temperature of the samples was determined using DSC-Q1000, TA instrument. Samples were weighed to $\pm 0.5 \mathrm{mg}$ accuracy, and experiments were carried out in nitrogen environment. The first stage of heating was carried out to remove the thermal history of the sample if any. The cooling step was done at a rate of $5{ }^{\circ} \mathrm{C} / \mathrm{min}$, and the final heating at a rate of $10^{\circ} \mathrm{C} / \mathrm{min}$ was carried out to determine the $T_{\mathrm{g}}$ of the sample.

\subsubsection{X-ray diffraction}

X-ray diffraction (XRD) studies were carried out using a D8 Advance X-ray Instrument with wavelength of $\lambda=0.154 \mathrm{~nm}$ and $2 \theta$ range from $2^{\circ}$ to $70^{\circ}$. The scanning rate was $1 \%$ min.

\subsubsection{Electrical conductivity}

Electrical conductivity measurement was carried out using a four probe AIT SR-2000N/PV machine at a current of $10 \mathrm{nA}$ and $2 \mathrm{~V}$.

\subsubsection{Scanning electron microscopy (SEM)}

Scanning electron microscopy were taken using a JSM-6460LV (Jeol) SEM. Prior to the experiment, the samples were cryo-fractured using liquid nitrogen and the cross section was sputter coated with gold for 2 min to make the surface conductive.

\section{Results and discussion}

The possible mechanism of $\mathrm{P}(\mathrm{S}-\mathrm{co}-\mathrm{MMA}) /$ graphene nanocomposites formation via melt blending and the effect of microwave irradiation are shown in Scheme 1. Melt blending at high shear and high temperature can lead to attachment of the polymer chains onto the graphene platelets. The irradiation caused free radical formation on polymer chains and surface modification of graphene which eventually leads to better interaction between them.

\subsection{FTIR analysis}

Figure 1(a) shows the FTIR spectra of graphene. Figure 1(b) and (c) show the FTIR spectra of non-irradiated and irradiated P(S-co-MMA) and its composites. In Figure 1(a), the peak in graphene spectra at 2928 and $2865 \mathrm{~cm}^{-1}$ represents the $\mathrm{C}-\mathrm{H}$ stretch vibrations of the methylene group.[30] The FTIR spectra's of non-irradiated and irradiated composites showed the similar trend of bands compared to control P(S-co-MMA), with an increase or even disappeared in the intensity of the some absorption band found after melt mixing and microwave irradiation.

In non-irradiated $\mathrm{PG}(0.1)$ and $\mathrm{PG}(1)$, the intensity of carbonyl stretching vibration peak at $1725 \mathrm{~cm}^{-1}$ was decreased to low intensity as compared to $\mathrm{P}(\mathrm{S}-\mathrm{co}-\mathrm{MMA})$. This 


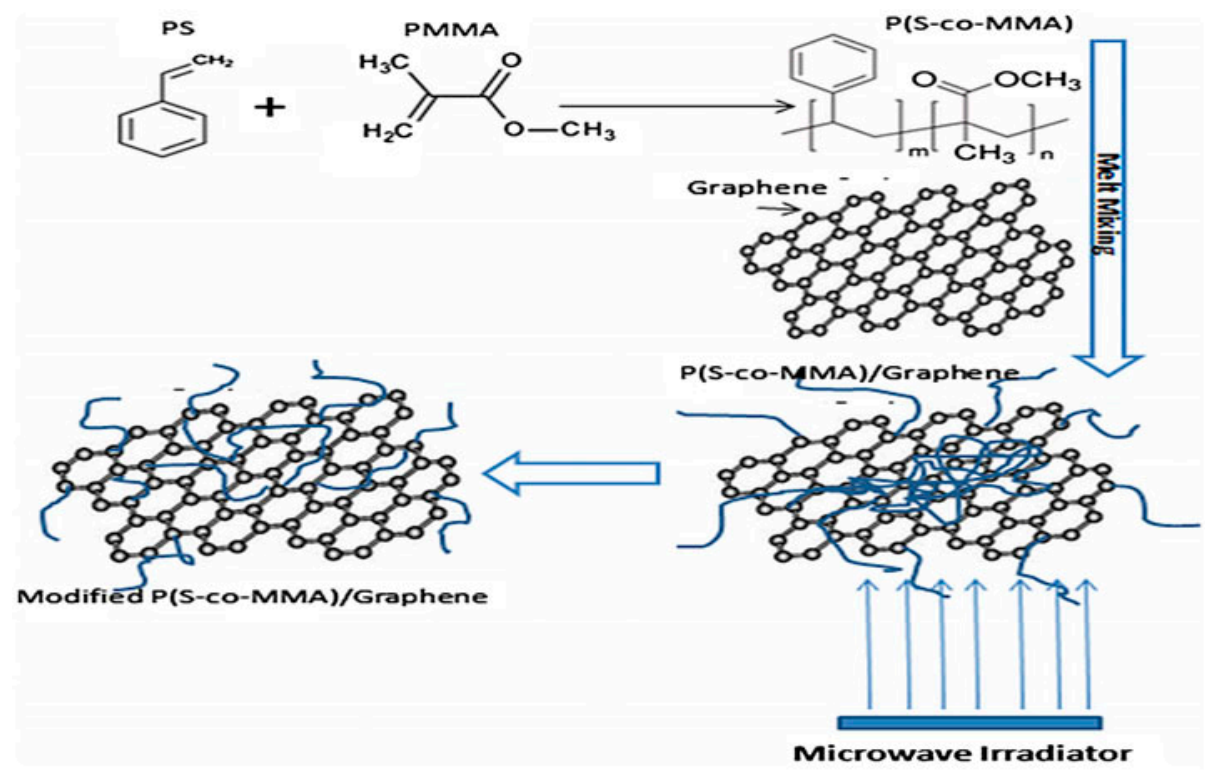

Scheme 1. Schematic representation of the improvement of interaction between P(S-co-MMA) and graphene after microwave irradiation.

may be due to the interaction of graphene with the methyl acrylate $\left(\mathrm{COOCH}_{3}\right)$ functionality in a polymer matrix after melt mixing.[31] In addition, the non-irradiated $\mathrm{PG}(0.1)$ and $\mathrm{PG}(1)$, after irradiation $(5 \mathrm{~min})$, showed a further decrease in the intensity of absorption band of the carbonyl group peak at $1725 \mathrm{~cm}^{-1}$. The physical interaction at the interface will lead to broadening of the IR band, and as a result, the absorbance decreases despite the integrated intensity remains the unchanged.

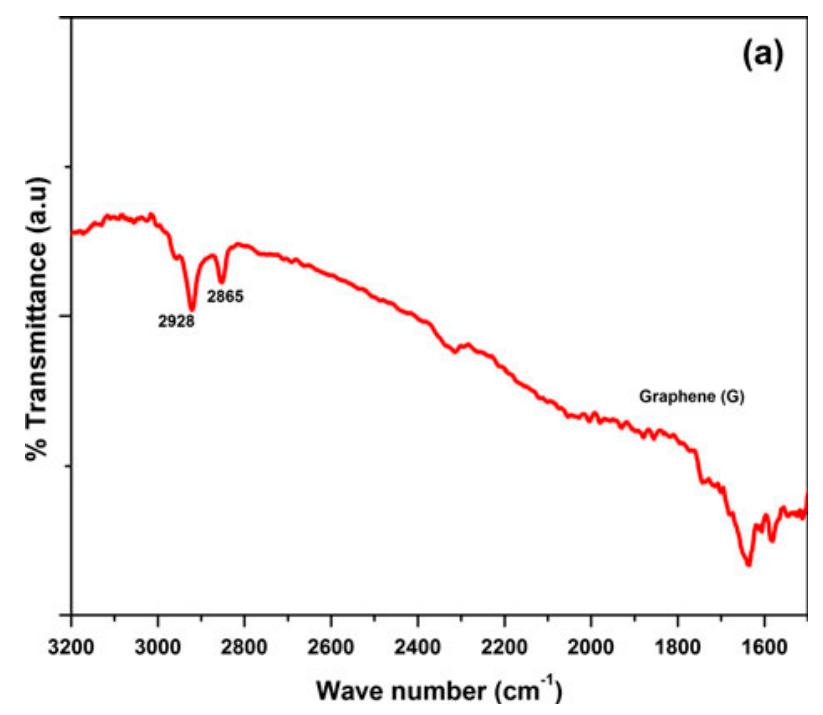

Figure 1(a). FTIR spectra of graphene. 

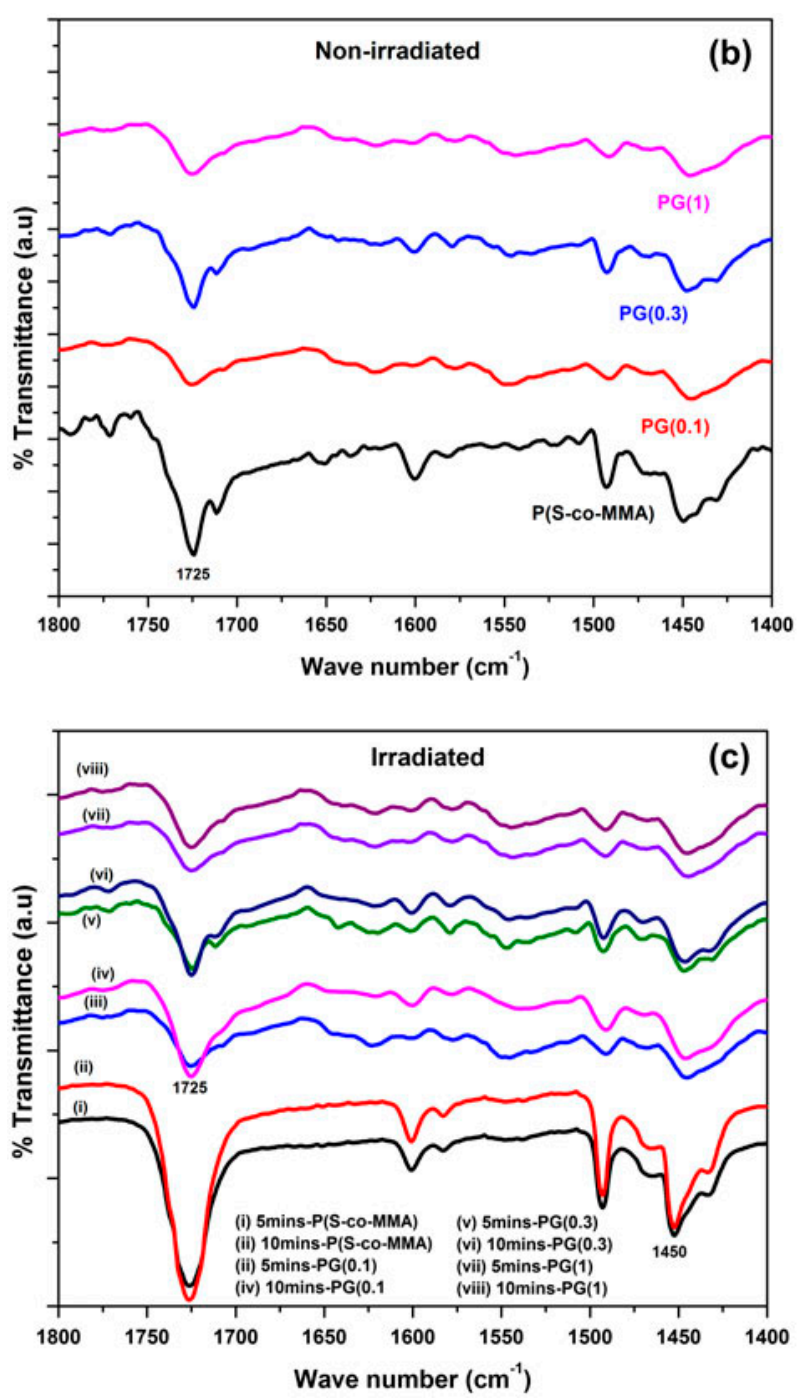

Figure 1(b-c). FTIR spectra of non-irradiated and irradiated control P(S-co-MMA) and its graphene composites.

At $10 \mathrm{~min}$ of irradiation, an increase in the intensity of carbonyl stretching vibrations peak at $1725 \mathrm{~cm}^{-1}$ was found in $\mathrm{P}(\mathrm{S}-\mathrm{co}-\mathrm{MMA})$ and $\mathrm{P}(\mathrm{S}-\mathrm{co}-\mathrm{MMA}) /$ graphene composites (Figure 1(c)). The enhancement in the absorption band of the carbonyl group after irradiation referred to the photo degradation of methylene group [32] present in $\mathrm{P}$ (S-co-MMA) polymer. This results in the formation of oxygen-based functionalities on exposure to microwave radiation.

\subsection{Raman analysis}

Figure 2(a) shows the Raman spectra of pristine graphene, control P(S-co-MMA), non-irradiated PG(0.1), and PG(1) composites. Figure 2(b) shows the spectra of 5-min 


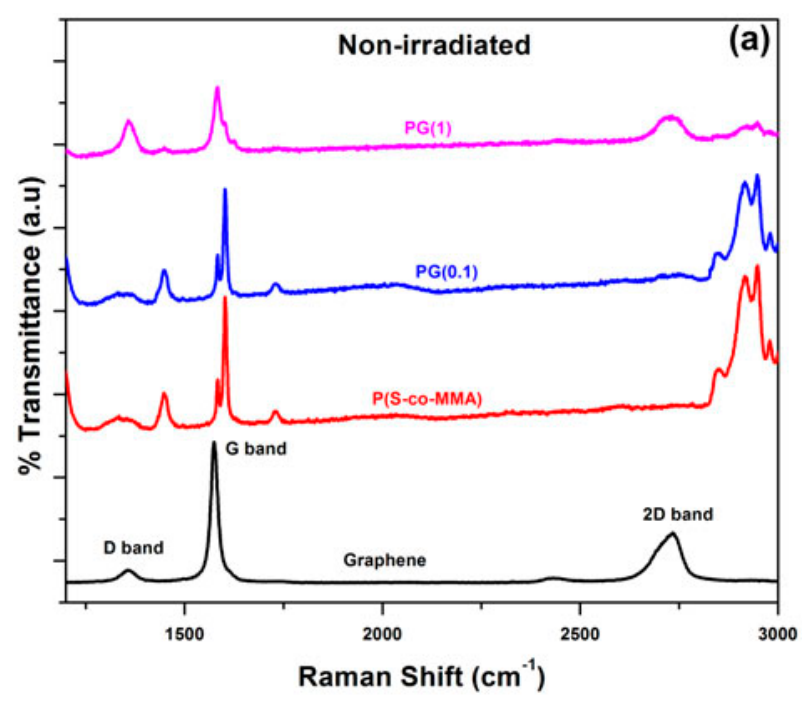

Figure 2(a). Raman spectra of graphene and non-irradiated control P(S-co-MMA) and its composites.

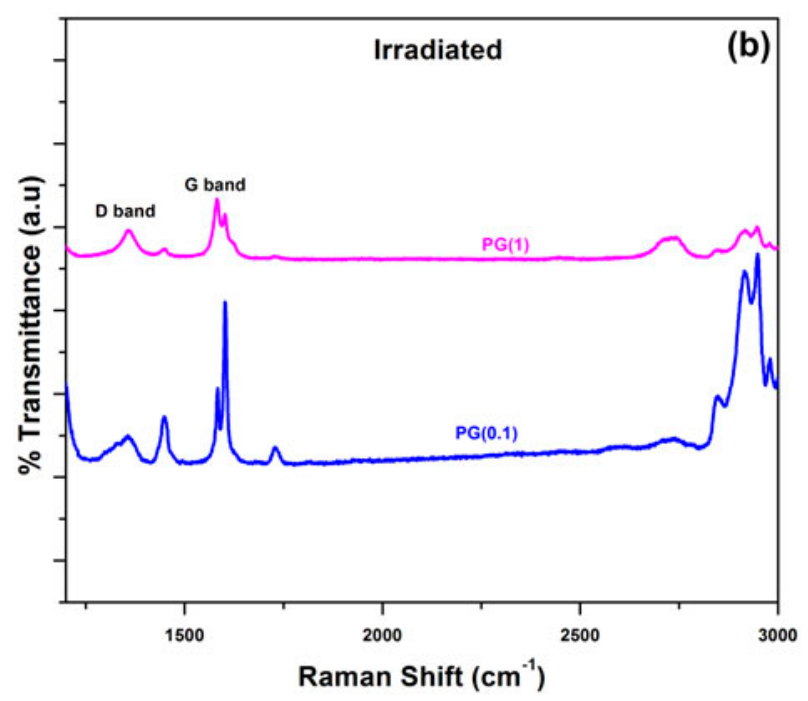

Figure 2(b). Raman spectra of irradiated PG(0.1) and PG(1).

irradiated PG(0.1) and PG(1) composites. The interesting features in Raman spectra of pristine graphene are the G-band, D-band, and 2D-bands. Then G-band is at $1583 \mathrm{~cm}^{-1}$ which correspond to the $E_{2 \mathrm{~g}}$ phonon at the center of the Brillouin zone or due to the $\mathrm{sp}^{2} \mathrm{C}=\mathrm{C}$ stretching vibrations.[33] The $\mathrm{D}$-band (disorder mode) is at $1357 \mathrm{~cm}^{-1}$ and corresponds to an out-plane breathing mode of $\mathrm{sp}^{2}$ atoms. The D-band is indicative of the presence of the defects in graphene $[34,35]$ and is the best tool to estimate the level of defects arising in graphene. These defects present on graphene are the potential 
Table 2. $I_{\mathrm{D}} / I_{\mathrm{G}}$ ratio of $\mathrm{P}(\mathrm{S}-\mathrm{co}-\mathrm{MMA}) /$ graphene composite before and after irradiation.

\begin{tabular}{lccc}
\hline Samples & D peak $(-1357)$ intensity & G peak $(-1583)$ intensity & $I_{\mathrm{D}} / I_{\mathrm{G}}$ \\
\hline Graphene & 95.24 & 863.17 & 0.11 \\
Non-irradiated PG(0.1) & 906.7 & 1125.3 & 0.76 \\
Non-irradiated PG(1) & 1164.8 & 2110.2 & 0.79 \\
5 min-irradiated PG(0.1) & 1831.5 & 2050.1 & 0.89 \\
5 min-irradiated PG(1) & 1984.2 & 2189.7 & 0.90 \\
\hline
\end{tabular}

active sites to form covalent bonding with free radicals of $\mathrm{P}(\mathrm{S}-\mathrm{co}-\mathrm{MMA})$ polymer generated during microwave irradiation. The 2D-band at around $2700 \mathrm{~cm}^{-1}$ is used to examine the quality of graphene.

In Figure 2(a), the very low intensity of the D-band, and broad peak of the 2D-band of pristine graphene, indicates its high quality and crystalline nature.[36] In the case of non-irradiated PG(0.1) and non-irradiated PG(1) (Figure 2(a)), the 2D-band of graphene has fully disappeared and has shifted to lower intensity, respectively. This is caused due to overlapped peak of the copolymer. An increase in the intensity of the D-band $\left(\sim 1357 \mathrm{~cm}^{-1}\right)$ was also observed in both non-irradiated $\mathrm{PG}(0.1)$ and non-irradiated PG(1). This increase in D-band intensity of non-irradiated PG(0.1) indicates the formation of disorder in graphene [37], and this may cause better interaction of polymer chains on the surface of graphene during melt blending. Similar trends have also been found by Patole et al. [38] The characteristic peak of control P(S-co-MMA) in Figure 2(a) was also seen in the Raman spectra of non-irradiated PG(0.1) which was not present in the non-irradiated PG(1) composite. This may be attributed to the fact that the graphene being good Raman scatter and dominating the spectrum at high loading content.

After 5 min of the irradiation of $\mathrm{PG}(0.1)$ and $\mathrm{PG}(1)$ composites, it was found that the intensity level of D-band and G-band both increased (Figure 2(b)). The increase in the intensity of D-band reveals the formation of more disorder in the graphene surface after irradiation. This shows that free radicals were generated by scission of polymer chains and attached to the defected surface of graphene due to microwave irradiation of composites. Similar trends have also been observed by McIntosh et al. [18] when SWNT was treated with benzoyl peroxide during melt mixing. The $I_{\mathrm{D}} / I_{\mathrm{G}}$ ratio of both non-irradiated $\mathrm{PG}(0.1)$ and non-irradiated $\mathrm{PG}(1)$ were significantly changed after irradiation as illustrated in Table 2. In addition to this, it was also observed that some characteristic peaks of control $\mathrm{P}(\mathrm{S}-\mathrm{co}-\mathrm{MMA})$ appeared in 5-min irradiated $\mathrm{PG}(1)$ spectra (Figure 2(b)) which was not seen in non-irradiated $\mathrm{PG}(1)$. This also confirmed the improvement in interaction between the graphene and the $\mathrm{P}(\mathrm{S}-\mathrm{co}-\mathrm{MMA})$ polymer matrix after 5 min of microwave irradiation.

\subsection{XRD analysis}

Figure 3 displays the XRD patterns of pristine graphene, non-irradiated $\mathrm{PG}(0.1), \mathrm{PG}(1)$, and 5-min irradiated samples of $\mathrm{PG}(0.1), \mathrm{PG}(1)$, respectively. The diffraction peak of pristine graphene was observed at about $2 \theta=26.7^{\circ}$.[39] It was found that when graphene was incorporated in $\mathrm{P}(\mathrm{S}-\mathrm{co}-\mathrm{MMA})$ polymer matrix via melt blending, the diffraction peak of graphene in an XRD pattern of non-irradiated $\mathrm{PG}(0.1)$ and $\mathrm{PG}(1)$ increased with the content of graphene (Figure 3). After $5 \mathrm{~min}$ of irradiation, the diffraction peak of graphene has almost disappeared in the XRD pattern of 5-min irradiated $\mathrm{PG}(0.1)$ 


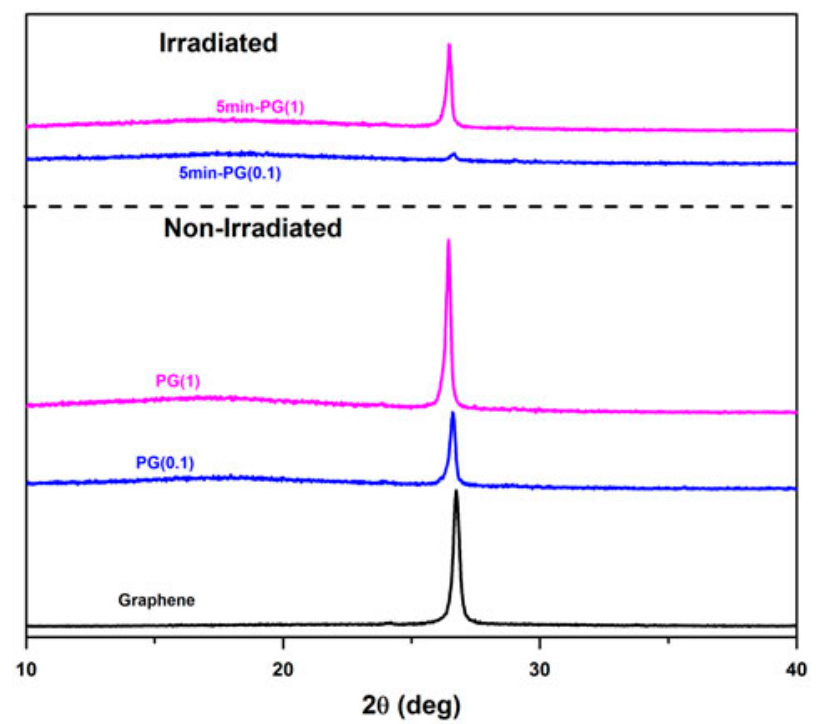

Figure 3. XRD patterns of graphene, non-irradiated and irradiated $\mathrm{PG}(0.1)$ and $\mathrm{PG}(1)$.

whereas shifted to a low intensity level for 5-min irradiated PG(1) composites. This indicates the formation of exfoliated graphene structure due to microwave irradiation which enhanced the interaction of graphene with the P(S-co-MMA) polymer chains.[40] The XRD pattern clearly demonstrates that after 5 min of irradiation of the $\mathrm{PG}(0.1)$ composite, the graphene is completely exfoliated in the $\mathrm{P}(\mathrm{S}-\mathrm{co}-\mathrm{MMA})$ polymer matrix as the diffraction peak of graphene has disappeared [40,41] thereby indicating strong interfacial interaction of graphene in the $\mathrm{P}(\mathrm{S}-\mathrm{co}-\mathrm{MMA})$ matrix.

\subsection{DMA analysis}

The mechanical properties of non-irradiated and irradiated P(S-co-MMA) and its graphene composites were evaluated by dynamic mechanical analysis (DMA) (Table 3).

Table 3. Storage modulus and $T_{\mathrm{g}}$ obtained from DMA of non-irradiated and irradiated $\mathrm{P}(\mathrm{S}-\mathrm{co}-\mathrm{MMA})$ and its composites.

\begin{tabular}{lccc}
\hline Sample & $E(\mathrm{MPa})$ at $40{ }^{\circ} \mathrm{C}$ & $E(\mathrm{MPa})$ at $120{ }^{\circ} \mathrm{C}$ & $T_{\mathrm{g}}\left({ }^{\circ} \mathrm{C}\right)$ \\
\hline Control P(S-co-MMA) & 1367 & 677 & 132 \\
Non-irradiated PG(0.1) & 1663 & 1102 & 135 \\
Non-irradiated PG(0.3) & 1452 & 906 & 134 \\
Non-irradiated PG(1) & 1308 & 1025 & 135 \\
5 min-irradiated P(S-co-MMA) & 1447 & 820 & 133 \\
5 min-irradiated PG(0.1) & 1567 & 1215 & 135 \\
5 min-irradiated PG(0.3) & 1523 & 940 & 135 \\
5 min-irradiated PG(1) & 1717 & 1066 & 135 \\
10 min-irradiated P(S-co-MMA) & 1219 & 718 & 132 \\
10 min-irradiated PG(0.1) & 1540 & 1067 & 134 \\
10 min-irradiated PG(0.3) & 1285 & 740 & 134 \\
10 min-irradiated PG(1) & 1037 & 828 & 135 \\
\hline
\end{tabular}


Figure 4(a) and (b) showed the storage modulus of non-irradiated and irradiated $\mathrm{P}(\mathrm{S}-\mathrm{co}-\mathrm{MMA})$ and its graphene composites, respectively.

At a glassy state $\left(40^{\circ} \mathrm{C}\right)$ (Figure $\left.4(\mathrm{a})\right)$, the storage modulus of non-irradiated PG $(0.1)$ and non-irradiated $\mathrm{PG}(0.3)$ composites increased to higher values compared to the control P(S-co-MMA) polymer. This increase in storage modulus after incorporation of graphene in the $\mathrm{P}(\mathrm{S}-\mathrm{co}-\mathrm{MMA})$ polymer matrix is attributed to the reinforcing effect of filler on the polymer matrix. However, a decrease in storage modulus was found with increase of graphene content from 0.1 to 0.3 and $1 \%$. This might be associated with the network relaxation [42] and plasticization effect of graphene agglomerate on $\mathrm{P}(\mathrm{S}-$-co-MMA) matrix at high loading content.[43]

At 5 min of microwave irradiation of P(S-co-MMA) and its graphene composites, the storage modulus significantly increased (Figure $4\left(\right.$ b)). For example, at $120^{\circ} \mathrm{C}$ after 5 min of irradiation of $\mathrm{PG}(0.1)$, the storage modulus was found to increase from 1002
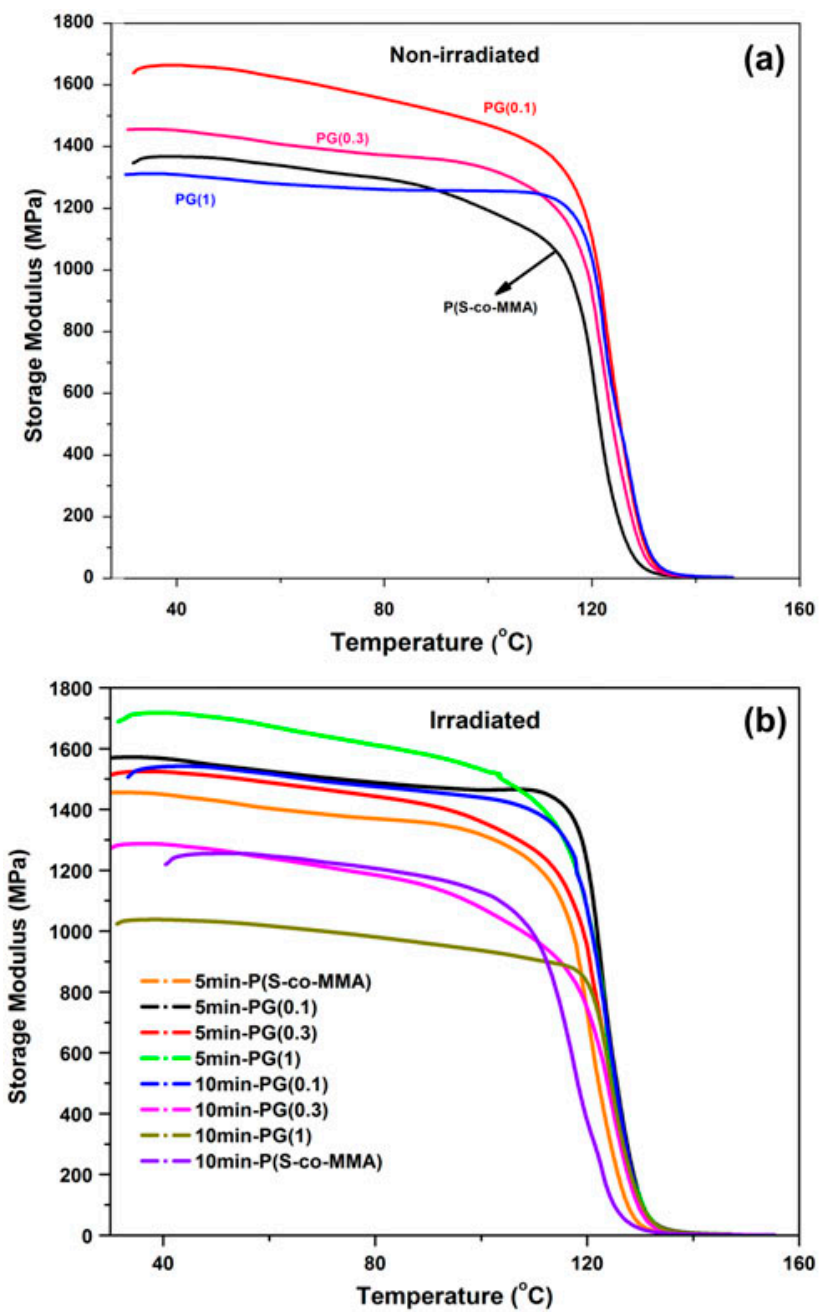

Figure 4. ( $\mathrm{a}$ and $\mathrm{b})$ Storage modulus non-irradiated control $\mathrm{P}(\mathrm{S}-\mathrm{co}-\mathrm{MMA})$ and its graphene composites. 
to $1215 \mathrm{MPa}$ (21\% increase compared to non-irradiated PG(0.1). Similarly, in case of $\mathrm{PG}(0.3)$ and $\mathrm{PG}(1)$ composites, the storage modulus at $40{ }^{\circ} \mathrm{C}$ increased from 1452 to $1523 \mathrm{MPa}(5 \%$ increase) and from 1308 to 1710 (31\% increase), respectively, after 5 min of irradiation. An increase in storage modulus of control P(S-co-MMA) and its graphene composites after $5 \mathrm{~min}$ of microwave exposure may have been due to the formation of a cross-linked network and improved polymer-graphene interaction induced by microwave irradiation. This is due to the formation of free radicals on polymer chains as well as the defects produced on the graphene surface,[44] as observed in FTIR and Raman spectra. This produced a stiffer and stronger polymer graphene nanocomposite. Similar results were also found in the irradiation of carbon nanofibers.[45]

However, at a higher irradiation time, i.e. $10 \mathrm{~min}$, the storage modulus of $\mathrm{P}(\mathrm{S}-\mathrm{co}-$ MMA) and its graphene composites started to decrease (11, 6, 11, and 20\% decrease for non-irradiated $\mathrm{P}(\mathrm{S}-\mathrm{co}-\mathrm{MMA})$ and $\mathrm{PG}(0.1), \mathrm{PG}(0.3)$ and $\mathrm{PG}(1)$, respectively). This is attributed to the chain scission and photo degradation of the methyl methacrylate in $\mathrm{P}(\mathrm{S}-\mathrm{co}-\mathrm{MMA})$ /graphene composites (confirmed by FTIR spectra). Thus resulted in the reduction in storage modulus of $\mathrm{P}(\mathrm{S}-\mathrm{co}-\mathrm{MMA})$ and its graphene composites.

\subsection{DSC analysis}

Figure 5(a) shows the glass transition temperature $\left(T_{\mathrm{g}}\right)$ of the control P(S-co-MMA) and its non-irradiated graphene composites. Figure $5(\mathrm{~b})$ shows the $T_{\mathrm{g}}$ of irradiated $\mathrm{P}(\mathrm{S}-\mathrm{co}-\mathrm{MMA})$ /graphene composites. These differential scanning calorimetry (DSC) results are the average of three different runs with an average of $\pm 0.5^{\circ} \mathrm{C}$. It was observed in Figure 5(a) that there was an increase of about $2.5^{\circ} \mathrm{C}$ of temperature in the $T_{\mathrm{g}}$ of non-irradiated $\mathrm{PG}(0.1), \mathrm{PG}(0.3)$, and $\mathrm{PG}(1)$ compared to the control $\mathrm{P}(\mathrm{S}-\mathrm{co}-\mathrm{MMA})$. This indicates that increasing the amount of graphene content on

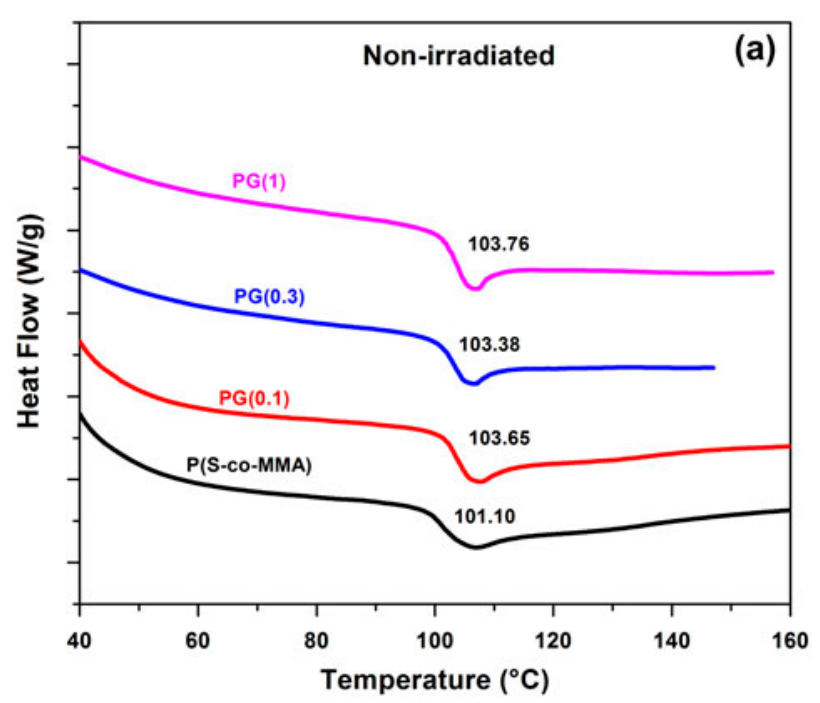

Figure 5(a). Glass transition observed from DSC for control P(S-co-MMA) and its non-irradiated graphene composites. 


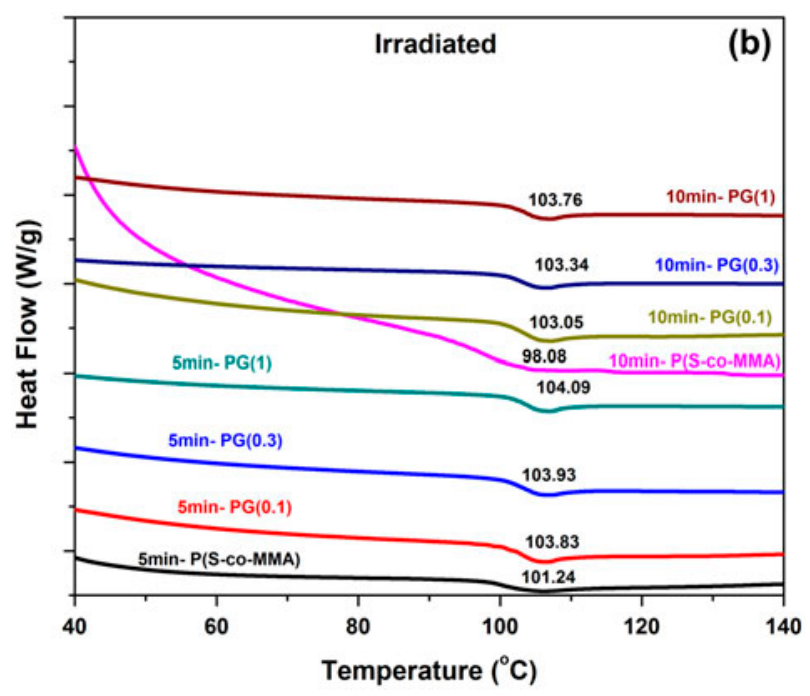

Figure 5(b). Glass transition observed from DSC of irradiated P(S-co-MMA) and its graphene composites.

$\mathrm{P}(\mathrm{S}-\mathrm{co}-\mathrm{MMA})$ /graphene has no prominent effect on the glass transition temperature of composites. After 5 and 10 min of irradiation, no prominent increase or decrease was observed in the $T_{\mathrm{g}}$ of all $\mathrm{P}(\mathrm{S}-\mathrm{co}-\mathrm{MMA})$ /graphene composites (Figure 5(b)).

\subsection{Electrical conductivity}

The electrical conductivity of the $\mathrm{P}(\mathrm{S}-\mathrm{co}-\mathrm{MMA}) /$ graphene composites was estimated using a four-probe method. The samples PG(0.1)and PG(1) showed conductivities of $2.01 \times 10^{-6}$ and $1.2 \times 10^{-4} \mathrm{~S} / \mathrm{cm}$, respectively, which is much higher than the control $\mathrm{P}$ (S-co-MMA) polymer matrix. The conductivity of $\mathrm{PG}(1)$ was found to ascend to $1.38 \times 10^{-3} \mathrm{~S} / \mathrm{cm}$ after $5 \mathrm{~min}$ of irradiation. This is due to the improved interfacial interaction of graphene in the $\mathrm{P}(\mathrm{S}-\mathrm{co}-\mathrm{MMA})$ polymer matrix after microwave exposure, and finally, improved electron conduction.

\subsection{SEM analysis}

Figure 6(a)-(f) shows the SEM images of the non-irradiated, 5- and 10-min irradiated sample of PG(0.1) and PG(1), respectively. In Figure 6(a), the SEM image of nonirradiated $\mathrm{PG}(0.1)$ shows a smooth discrete surface morphology. This can be attributed to the reinforcement effect of graphene in the $\mathrm{PG}(0.1)$ composite. Absence of any agglomerated graphene particle shows the uniform dispersion of graphene. In Figure 6(b), presence of some fracture and formation of rough surfaces after $5 \mathrm{~min}$ of irradiation of $\mathrm{PG}(0.1)$ is due to the encapsulation of polymer matrix onto the graphene. This indicates the enhancement of interfacial interaction between the graphene and the polymer matrix, which results in a stronger $\mathrm{PG}(0.1)$ composite. In contrast, a smoother surface of non-irradiated PG(1) is seen in Figure 6(d). The presence of voids and a smooth surface shows the formation of graphene agglomerates and weak adhesion between the graphene and the P(S-co-MMA) matrix.[46] However, after 5 min of 


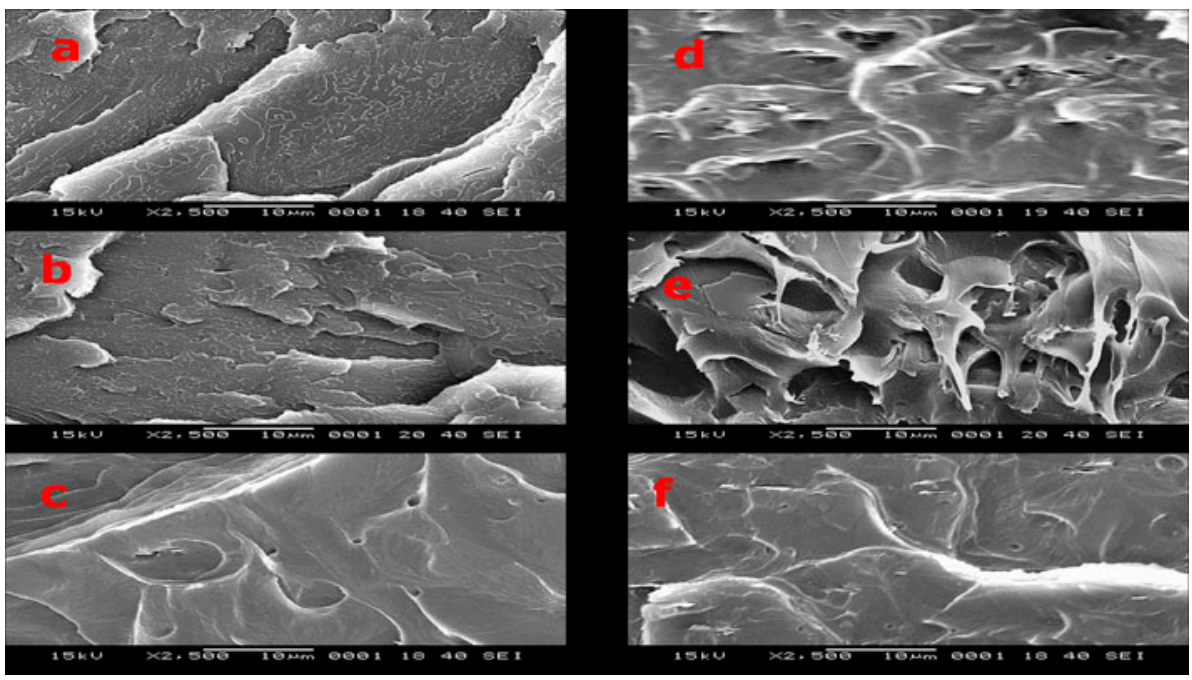

Figure 6. $\quad$ SEM images of the non-irradiated and irradiated samples $\operatorname{PG}(0.1)$ (a)-(c) and PG(1) (d)-(f) composites.

irradiation of PG(1) (Figure 6(e)), the morphology is completely changed to a rough fiber-like surface. This demonstrates that the polymer chains adhered to graphene more strongly and formed an interconnecting cross-linked network. This confirms that radiation facilitates the improved interaction and grafting of graphene throughout the PG(1) composites. This cross-linked fiber-like network of 5-min irradiated PG(1) composites results in improved mechanical properties and higher electrical conductivity which is also confirmed by the DMA and conductivity studies. In Figure 6(c)-(f), at a high irradiation time (10 min) of $\mathrm{PG}(0.1)$ and $\mathrm{PG}(1)$, respectively, the surface becomes smoother with some cracks on it. This results in weak interaction and adhesion between the polymer matrix and the dispersed phase of graphene. The SEM image (Figure 6(f)) also shows the fractured and degraded surface of 10-min irradiated PG(1) composite, captured from another part of same sample. This confirms that at high irradiation time (i.e. $10 \mathrm{~min})$, the $\mathrm{P}(\mathrm{S}-\mathrm{co}-\mathrm{MMA})$ polymer started to degrade. This results in weak $\mathrm{P}(\mathrm{S}-\mathrm{co}-\mathrm{MMA})$ /graphene composite which is corroborated by the DMA studies in the previous section.

\section{Conclusion}

Poly (styrene-co-methyl meth acrylate)/graphene nanocomposites were prepared by melt mixing, and the effects of graphene content and microwave irradiation were studied. FTIR and Raman spectroscopy studies confirmed the formation of defects/disorder in graphene surface after microwave irradiation. This resulted in an improvement of graphene-polymer interaction via covalent bond formation. Investigation of mechanical properties by means of DMA and exfoliation by XRD pointed out that the microwave irradiation up to $5 \mathrm{~min}$ of $\mathrm{P}(\mathrm{S}-\mathrm{co}-\mathrm{MMA}) /$ graphene nanocomposites particularly for $1 \mathrm{wt}$ $\%$ graphene composite is suitable for improving the interfacial interaction between the graphene and the host $\mathrm{P}(\mathrm{S}-\mathrm{co}-\mathrm{MMA})$ matrix with a significant increase in the storage modulus. A decrease in mechanical properties of the $\mathrm{P}(\mathrm{S}-\mathrm{co}-\mathrm{MMA}) /$ graphene 
composites at a higher irradiation time $(10 \mathrm{~min})$ is due to the reduction of molecular weight, resulting from the chain scission or photo degradation of the host $\mathrm{P}(\mathrm{S}-\mathrm{co}-\mathrm{MMA})$ polymer chains. This is also confirmed by the rough damaged surface as well as appearance of cracks and holes shown by SEM study. The study provides an alternative, easy and green method to provide a stronger interfacial interaction between the graphene and the $\mathrm{P}(\mathrm{S}-\mathrm{co}-\mathrm{MMA})$ matrix, which significantly changed the mechanical property of composites.

\section{Acknowledgments}

The authors would like to thank the Center of Research Excellence in Nanotechnology for the support in this study. The corresponding author would like to thank to KFUPM for the support in establishing the polymer Laboratory at the Chemical Engineering Department, KFUPM.

\section{Disclosure statement}

No potential conflict of interest was reported by the authors.

\section{References}

[1] Si Y, Samulski ET, Hill C, et al. Synthesis of water soluble graphene. Nano Lett. 2008;8:1679-1682.

[2] Geim AK, MacDonald AH. Graphene: exploring carbon flatland. Phys. Today. 2007;60: 35-41.

[3] Stankovich S, Dikin DA, Dommett GHB, et al. Graphene-based composite materials. Nature. 2006;442:282-286.

[4] Kim KS, Zhao Y, Jang H, et al. Large-scale pattern growth of graphene films for stretchable transparent electrodes. Nature. 2009;457:706-710.

[5] Robinson JT, Perkins FK, Snow ES, et al. Reduced graphene oxide molecular sensors. Nano Lett. 2008;8:3137-3140.

[6] Sahoo S, Karthikeyan G, Nayak GC, et al. Modified graphene/polyaniline nanocomposites for supercapacitor application. Macromol. Res. 2012;20:415-421.

[7] Chen Y, Xu Y, Zhao K, et al. Towards flexible all-carbon electronics: Flexible organic fieldeffect transistors and inverter circuits using solution-processed all-graphene source/drain/gate electrodes. Nano Res. 2010;3:714-721.

[8] Wang Z, Zhang H, Li N, et al. Laterally confined graphene nanosheets and graphene $/ \mathrm{SnO}_{2}$ composites as high-rate anode materials for lithium-ion batteries. Nano Res. 2010;3: 748-756.

[9] Nuvoli D, Alzari V, Sanna R, et al. Synthesis and characterization of graphene-based nanocomposites with potential use for biomedical applications. J. Nanopart. Res. 2013; 15:1512-1519.

[10] Burdick JA, Anseth KS. Photoencapsulation of osteoblasts in injectable RGD-modified PEG hydrogels for bone tissue engineering. Biomaterials. 2002;23:4315-4323.

[11] George PA, Donose BC, Cooper-White JJ. Self-assembling polystyrene-block-poly(ethylene oxide) copolymer surface coatings: Resistance to protein and cell adhesion. Biomaterials. 2009;30:2449-2456.

[12] Thompson LF, Willson CG. Polymers for microelectronics. In: Thompson LF, Willson CG, Tagawa S, editors. ACS Symp. Washington (DC): American Chemical Society; 1993. p. 305-321.

[13] Kondo Y, Yoshikawa H, Awaga K, et al. Preparation, photocatalytic activities, and dyesensitized solar-cell performance of submicron-scale $\mathrm{TiO}_{2}$ hollow spheres. Langmuir. 2008;24:547-550.

[14] Dresselhaus MS, Dresselhaus G. PA. Synthesis, structure, properties, and applications. Top. Appl. Phys. 2001;80:2-3. 
[15] Kuilla T, Bhadra S, Yao D, et al. Recent advances in graphene based polymer composites. Prog. Polym. Sci. 2010;35:1350-1375.

[16] Zhang Z, Zhang J, Chen P, et al. Enhanced interactions between multi-walled carbon nanotubes and polystyrene induced by melt mixing. Carbon. 2006;44:692-698.

[17] Shen B, Zhai W, Chen C, et al. Melt blending in situ enhances the interaction between polystyrene and graphene through $\pi-\pi$ stacking. ACS Appl. Mater. Interfaces. 2011;3: 3103-3109.

[18] McIntosh D, Khabashesku VN, Barrera EV. Benzoyl peroxide initiated in situ functionalization, processing, and mechanical properties of single-walled carbon nanotube-polypropylene composite fibers. J. Phys. Chem. C. 2007;111:1592-1600.

[19] Banerjee D, Jha A, Chattopadhyay KK. Synthesis and characterization of water soluble functionalized amorphous carbon nanotube-poly(vinyl alcohol) composite. Macromol. Res. 2012;20:1021-1028.

[20] Feng L, Li W, Ren J, et al. Electrochemically and DNA-triggered cell release from ferrocene/ $\beta$-cyclodextrin and aptamer modified dual-functionalized graphene substrate. Nano Res. 2014;1:4-6.

[21] Oh SM, Lee H, Jeong HM, et al. The properties of functionalized graphene sheet/poly(ethyl methacrylate) nanocomposites: The effects of preparation method. Macromol. Res. 2011;19:379-384.

[22] Wu G, Tang Y, Weng R. Dispersion of nano-carbon filled polyimide composites using selfdegradated low molecular poly(amic acid) as impurity-free dispersant. Polym. Degrad. Stab. 2010;95:1449-1455.

[23] Won J, Yoon Y, Kang YS. Changes in facilitated transport behavior of silver polymer electrolytes by UV irradiation. Macromol. Res. 2013;10:80-84.

[24] Achilias DS. Polymer degradation under microwave irradiation. Adv. Polym. Sci. 2014: $1-38$.

[25] Teweldebrhan D, Balandin AA. Modification of graphene properties due to electron-beam irradiation. Appl. Phys. Lett. 2009;94:013101.

[26] Rafiemanzelat F, Zonuz AF, Abdollahi E. Fast and eco-friendly synthesis of new hydrolysable and biodegradable copolyurethanes derived from L-leucine cyclodipeptide and different molecular weights of PEG in TBAB under microwave irradiation. Macromol. Res. 2012;20:902-911.

[27] Cao HL, Wang P, Li Y. Preparation of poly(lactic acid)/Na-montmorillonite nanocomposite by microwave-assisted in-situ melt polycondensation. Macromol. Res. 2010;18:1129-1132.

[28] TK BS, Nair AB, Abraham BT, et al. Microwave exfoliated reduced graphene oxide epoxy nanocomposites for high performance applications. Polymer. 2014;55:3614-3627.

[29] Zubair M, Jose J, Emwas AH, et al. Effect of modified graphene and microwave irradiation on the mechanical and thermal properties of poly(styrene-co-methyl methacrylate)/graphene nanocomposites. Surf. Interface Anal. 2014;46:630-639.

[30] Naebe M, Wang J, Amini A, et al. Mechanical property and structure of covalent functionalised graphene/epoxy nanocomposites. Sci. Rep. 2014;4:4375.

[31] Krimm S. Infrared spectra of high polymers. 1960;2:51-172.

[32] Suarez JCM, Mano EB, Da Costa Monteiro EE, et al. Influence of $\gamma$-irradiation on poly (methyl methacrylate). J. Appl. Polym. Sci. 2002;85:886-895.

[33] Dresselhaus MS, Dresselhaus G, Saito R. Physics of carbon nanotubes. Carbon. 1995;33:883-891.

[34] Thomsen C, Reich S. Double resonant Raman scattering in graphite. Phys. Rev. Lett. 2000;85:5214-5217.

[35] Ferrari A, Robertson J. Resonant Raman spectroscopy of disordered, amorphous, and diamond like carbon. Phys. Rev. B. 2001;64:075414.

[36] Ferrari AC, Meyer JC, Scardaci V, et al. Raman spectrum of graphene and graphene layers. Phys. Rev. Lett. 2006;97:187401.

[37] Patole AS, Patole SP, Kang H, et al. A facile approach to the fabrication of graphene/polystyrene nanocomposite by in situ microemulsion polymerization. J. Colloid Interface Sci. 2010;350:530-537.

[38] Patole AS, Patole SP, Jung SY, et al. Self assembled graphene/carbon nanotube/polystyrene hybrid nanocomposite by in situ microemulsion polymerization. Eur. Polym. J. 2012;48:252-259. 
[39] $\mathrm{Hu} \mathrm{H}$, Wang $\mathrm{X}$, Wang $\mathrm{J}$, et al. Preparation and properties of graphene nanosheetspolystyrene nanocomposites via in situ emulsion polymerization. Chem. Phys. Lett. 2010;484:247-253.

[40] Liang J, Huang Y, Zhang L, et al. Molecular-level dispersion of graphene into poly(vinyl alcohol) and effective reinforcement of their nanocomposites. Adv. Funct. Mater. 2009;19:2297-2302.

[41] Du X, Yu Z, Dasari A, et al. New method to prepare graphite nanocomposites. Chem. Mater. 2008;20:2066-2068.

[42] Tang J, Zhou H, Liang Y, et al. Properties of graphene oxide/epoxy resin composites. 2014;2014:1-5.

[43] Saladino ML, Motaung TE, Luyt AS, et al. The effect of silica nanoparticles on the morphology, mechanical properties and thermal degradation kinetics of PMMA. Polym. Degrad. Stab. 2012;97:2477.

[44] Compagnini G, Giannazzo F, Sonde S, et al. Ion irradiation and defect formation in single layer graphene. Carbon. 2009;47:3201-3207.

[45] Evora MC, Klosterman D, Lafdi K, et al. Functionalization of carbon nanofibers through electron beam irradiation. Carbon. 2010;48:2037-2046.

[46] Wang N, Gao N, Fang Q, et al. Compatibilizing effect of mesoporous fillers on the mechanical properties and morphology of polypropylene and polystyrene blend. Mater. Des. 2011;32:1222-1228. 